\title{
Qualidade pós-colheita de oito variedades de pêssego
}

\author{
João Paulo Gava Cremasco, Rosana Gonçalves Pires Matias, Danielle Fabiola Pereira da Silva*,
} João Alison Alves Oliveira, Cláudio Horst Bruckner

Universidade federal de Viçosa, Voçosa, MG, Brasil

*Autor correspondente, e-mail: danieele@ufv.br

\section{Resumo}

As características físicas e químicas dos frutos variam durante o período de pós-colheita, e essa variação depende, entre outros fatores, das condições meteorológicas durante o desenvolvimento dos frutos. Este trabalho objetivou avaliar as alterações nas características físicas e químicas de oito cultivares de pêssego em duas safras. As cultivares Campinas 1, Coral, Maciel, Marli, Premier, Régis, Rei da Conserva e Tropic Beauty foram plantadas sobre o porta-enxerto Okinawa no pomar experimental da Universidade Federal de Viçosa (UFV), Viçosa-MG em 2008 e avaliadas quanto às características massa de fruto, cor da epiderme, firmeza, teor de sólidos solúveis, acidez titulável, teor de ácido ascórbico e carotenoides totais. O experimento foi conduzido durante as safras de 2011 e 2012, em delineamento inteiramente casualizado, com oito tratamentos (cultivares), três repetições e 10 frutos por parcela. Houve diferenças entre as características avaliadas nas duas safras, sendo as maiores variações observadas na firmeza da polpa e nos teores de ácido ascórbico e de carotenóides totais. As cultivares Maciel e Marli produzem frutos com maiores valores de massa, Tropic Beauty com maior firmeza e Rei da Conserva, Coral e Marli com maiores teores de sólidos solúveis. A cultivar Rei da Conserva se destacou em relação à maioria das características em ambas as safras. A tonalidade amarela no pêssego está associada com carotenóides totais.

Palavras-chave: Adaptação, amadurecimento, Prunus persica (L.) Batsch, qualidade de fruto

\section{Postharvest quality of eight peaches cultivars}

\begin{abstract}
The fruit physical and chemical characteristics can vary during the maturation period and this variation depends, among other factors, on the weather conditions during fruit development. This study aimed to evaluate the changes in physical and chemical characteristics of eight peach cultivars during two seasons. The cultivars Campinas 1, Coral, Maciel, Marli, Premier, Regis, Rei da Conserva and Tropic Beauty were planted on Okinawa rootstock at the experimental orchard of the Federal University of Viçosa (UFV), Viçosa-MG, Brazil, in 2008 and the following characteristics were evaluated: fruit weight, skin color, firmness, soluble solids, titratable acidity, ascorbic acid and total carotenoids. The experiment was conducted during 2011 and 2012 growing seasons in a completely randomized design with eight treatments (cultivars), three repetitions and 10 fruits per plot. There were differences between the variables for the two seasons, with the largest variations observed for firmness, ascorbic acid and total carotenoids. Cultivars Maciel and Marli produced fruit with higher mass, Tropic Beauty with greater firmness and Rei da Conserva, Coral and Marli with higher soluble solids contents. The cultivar Rei da Conserva presented higher values for most of the evaluated variables in both seasons. The yellow color, evaluated by the hue angle, is associated with total carotenoids content in peaches.
\end{abstract}

Keywords: Adaptation, ripening, Prunus persica (L.) Batsch, fruit quality 


\section{Introdução}

O pêssego é uma fruta climatérica de clima temperado pertencente à espécie Prunus persica (L.) Batsch, originária da Ásia. $\bigcirc$ pessegueiro apresenta grande variabilidade em características, como hábito de crescimento, formato das folhas e gemas, resistência a doenças e exigência em frio hibernal, assim como em produtividade e massa média de frutos (Della Bruna et al., 2012).

O avanço na fronteira de produção do pessegueiro, para regiões de clima subtropical e de inverno ameno, deve-se principalmente ao lançamento de novas cultivares, menos exigentes em frio hibernal e à criação de novas tecnologias que possibilitem o desenvolvimento da cultura (Leonel \& Tecchio, 2011). A região Sudeste do Brasil apresenta boas condições para a exploração econômica de fruteiras de clima temperado, devido principalmente à elevada altitude (Wagner Júnior et al., 2011). O Brasil produziu na safra 2013, 217.706 toneladas. O Rio Grande do Sul é o primeiro produtor nacional, com 136.841 toneladas, seguido pelo estado de São Paulo com uma produção de 26.849 toneladas (IBGE, 2015). Em Minas Gerais, a cultura encontra-se em desenvolvimento, concentrando sua produção principalmente na zona sul do Estado, pelas características edafoclimáticas desejáveis dessa região (Souza et al., 2009). Segundo dados do IBGE, 2015, a produção do estado de Minas Gerais em 2013 foi de 20.139 toneladas, sendo o quarto maior produtor, porém, com a maior produtividade $\left(22,55\right.$ t. ha $\left.^{-1}\right)$.

O mercado mundial de frutas dispõe de grande variedade de produtos, o que, juntamente com fatores socioeconômicos, faz com que o consumidor exija boa qualidade e também defina os padrões da mesma. Recentemente, a população mundial adquiriu a visão de que alimentos oferecem também elementos biologicamente ativos, que proporcionam benefícios adicionais à saúde (Silva et al., 2010), aumentando o interesse dos pesquisadores pelos teores de caroteno, de vitamina $\mathrm{C}$ e de antocianinas. Segundo Segantini et al. (2012), a ingestão dietética de pêssego pode reduzir a geração de EROS (espécies reativas de oxigênio) em sangue humano e proporcionar proteção contra um número de doenças crônicas.

A formação da muda em pessegueiros se dá, na maioria das vezes, pela combinação de dois genótipos, um que contribui com o sistema radicular, servindo de sustentação e absorção de água e nutrientes e o outro, a copa, responsável pela produção de frutos. A união dos genótipos é realizada por meio de enxertias. Os porta-enxertos são responsáveis pela absorção de água e nutrientes, resistência a patógenos do solo e tolerância a estresses ambientais (Mestre et al., 2015). Eles podem influenciar no desenvolvimento da cultivar, alterando a área de seção do tronco, altura, formato e crescimento da planta, ângulo de abertura dos ramos, nutrição da planta, potencial hídrico do xilema, fenologia, qualidade dos frutos, precocidade produtiva, produção, resistência a doenças e sobrevivência da planta (Gullo et al., 2014). Através da enxertia são conjugados aspectos favoráveis de duas ou mais plantas as quais podem ser da mesma espécie ou de espécies diferentes. As características que se pretende combinar podem estar relacionadas a fatores como vigor, tolerância a fatores bióticos e abióticos, produtividade, qualidade de frutos, entre outros. Assim de acordo com Leite et al. (2010) é fundamental a realização de estudos para avaliar a qualidade dos frutos em diferentes safras a fim de adotar medidas de melhoramento e manutenção de acordo com os padrões de comercialização.

As alterações comumente observadas durante a maturação dos frutos estão relacionadas com a produção de etileno e de voláteis, mudanças na cor, na taxa respiratória, na permeabilidade dos tecidos e na textura que afetam características físicas, químicas e sensoriais do fruto in natura e processado, destacando-se: aparência da coloração da epiderme, sabor, voláteis, textura, SS e AT (Toralles et al., 2008). Grande parte dessas alterações é devida a condições de pré-colheita que influenciam a qualidade pós-colheita de pêssegos, tais como: clima, solo, cultivar, manejo da cultura e maturidade (Matias et al., 2014). De acordo com Silva et al. (2013), essas alterações 
dependem, entre outros fatores, das condições meteorológicas durante o desenvolvimento dos frutos. Assim, o presente trabalho teve como objetivo estudar as alterações nas características físicas e químicas de cultivares de pêssego nas safras de 2011 e 2012 em região de clima subtropical.

\section{Material e Métodos}

O estudo foi realizado durante as safras de 2011 e 2012, com oito cultivares de pessegueiro ('Campinas 1', 'Coral', 'Maciel', 'Marli', 'Premier', 'Régis', 'Rei da Conserva' e 'Tropic Beauty') cultivadas no pomar experimental da Universidade Federal de Viçosa (UFV), ViçosaMG (2045's e 4251 'O; 649 m de altitude).
As cultivares Coral, Marli, Premier e Tropic Beauty são produtoras de frutas para mesa, enquanto que as cultivares Maciel e Régis possui dupla finalidade (comercialização para consumo in natura e para fins industriais) e as cultivares Rei da Conserva e Campinas 1 são destinadas para indústria. A época de colheita para cada cultivar foi 'Campinas 1' e 'Maciel' (novembro), 'Coral', 'Marli' e 'Premier' (outubro), 'Régis', e 'Tropic Beauty' (setembro) e 'Reida da Conserva' (dezembro).

As variedades copas foram enxertadas sobre o porta-enxerto 'Okinawa' e o plantio realizado em 2008. Os dados referentes às condições climáticas estão apresentados na Figura 1.
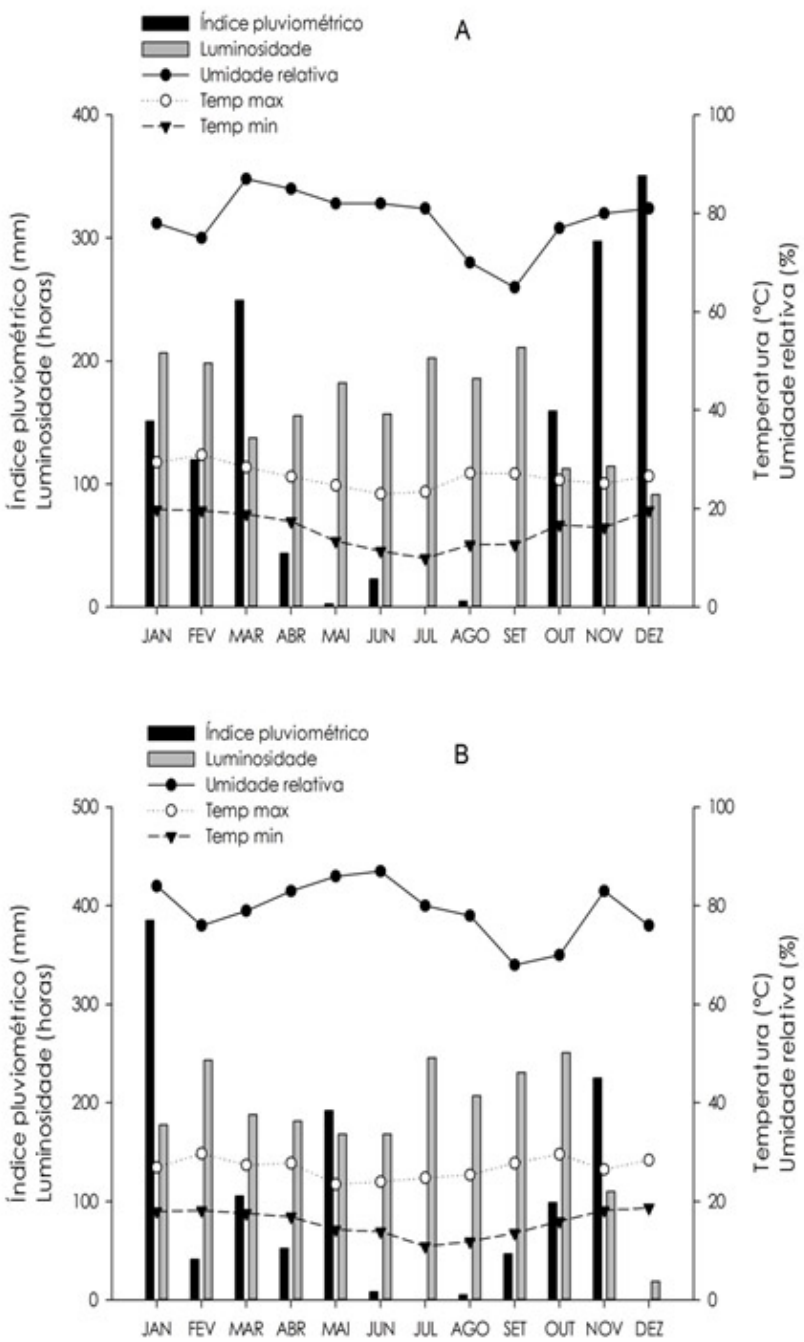

Figura 1. Valores de precipitação pluvial, luminosidade, umidade relativa do ar, temperatura máxima e mínima, referentes às safras de 2011 (A) e 2012 (B). Fonte: Estação meteorológica da Universidade Federal de Viçosa, Viçosa-MG. *Dezembro 2012 medidas até dia 05/12/2012. 
Os frutos foram colhidos usando como critério a mudança da coloração de fundo de verde para amarelo-claro ou branco-creme e avaliados quanto às características químicas $e$ físicas descritas a seguir. A massa do fruto (MF), em gramas (g), foi obtida com o auxílio de balança digital com precisão de 0,1 g. A cor da epiderme (medida na região equatorial em lados opostos do fruto) foi dada pela coordenada $L^{*}$ e ângulo Hue $\left(h^{\circ}\right)$, determinados por reflectometria, utilizando-se reflectômetro Minolta (Color Reader CR- 10) (McGuirre, 1992). A firmeza da polpa (N) foi determinada na região equatorial de uma das faces do fruto, após a remoção da epiderme, através de penetrômetro digital EffeGi, modelo FT-01 1, ponteira de 8 mm de diâmetro. O teor de sólidos solúveis (SS), expresso em (\%), foi analisado no suco retirado manualmente do fruto, por meio de refratômetro digital ATAGO (Palete PR-101). A acidez titulável (AT) foi obtida por titulação com solução de $\mathrm{NaOH} 0,1 \mathrm{~N}$, expressando-se o resultado em percentagem de ácido málico. O teor de ácido ascórbico (Vitamina C) foi determinada por titulação com reagente de Tillmans [2,6 diclorofenolindofenol (sal sódico) a 0,1\%] e os resultados expressos em mg de ácido ascórbico por $100 \mathrm{~g}$ de polpa. Os carotenoides totais (CT) foram obtidos pelas equações de Lichtenthaler (1987), em $\mu \mathrm{g} \cdot \mathrm{mL}^{-1}$ de extrato, a partir de leituras em espectrofotômetro nos comprimentos de onda de 470, 646,8 e 663,2 $\eta \mathrm{m}$. Os resultados foram multiplicados por $25 \mathrm{e}$ divididos pela massa de polpa, sendo expressos em mg. $100 \mathrm{~g}^{-1}$ de polpa.

Foi usado o delineamento inteiramente casualizado, em esquema fatorial $2 \times 8$, duas colheitas (safras), oito tratamentos (cultivares), três repetições e dez frutos por parcela, avaliados em duas safras. Foram utilizadas três plantas por cultivar e em cada uma foram colhidos dez frutos, totalizando 30 frutos por cultivar. Os dados obtidos foram submetidos à análise de variância e as médias comparadas pelo teste Tukey ao nível de $5 \%$ de probabilidade. As estimativas dos coeficientes de correlação fenotípicos foram calculados pelo método de Pearson (Steel \& Torrie, 1960) e testados em 1 e $5 \%$ de probabilidade pelo teste $\dagger$ com $n-2$ graus de liberdade e determinado para todas as combinações de características para obter informações sobre a natureza e intensidade entre eles. As análises foram realizadas com o auxílio do aplicativo computacional em estatística aplicado à genética - GENES (Cruz, 2013).

\section{Resultados e Discussão}

Nos dois anos avaliados, houve comportamento diferenciado entre as cultivares com relação às características físicas e químicas dos frutos (Tabelas 1 e 2). Quanto à massa de fruto, as cultivares Maciel e Marli foram significativamente superiores $(p \leq 0,05)$ em ambas as safras. A massa do fruto tem implicações na produtividade e no custo de processamento (Toralles et al., 2008) e a interceptação solar em espécies de Prunus é a principal maneira de se elevar a produtividade (Citadin et al., 2014), sendo assim, a disponibilidade de luz é o ponto crítico para produzir frutas de qualidade; o que favorece os produtores de pêssego da região Sudeste do Brasil. 

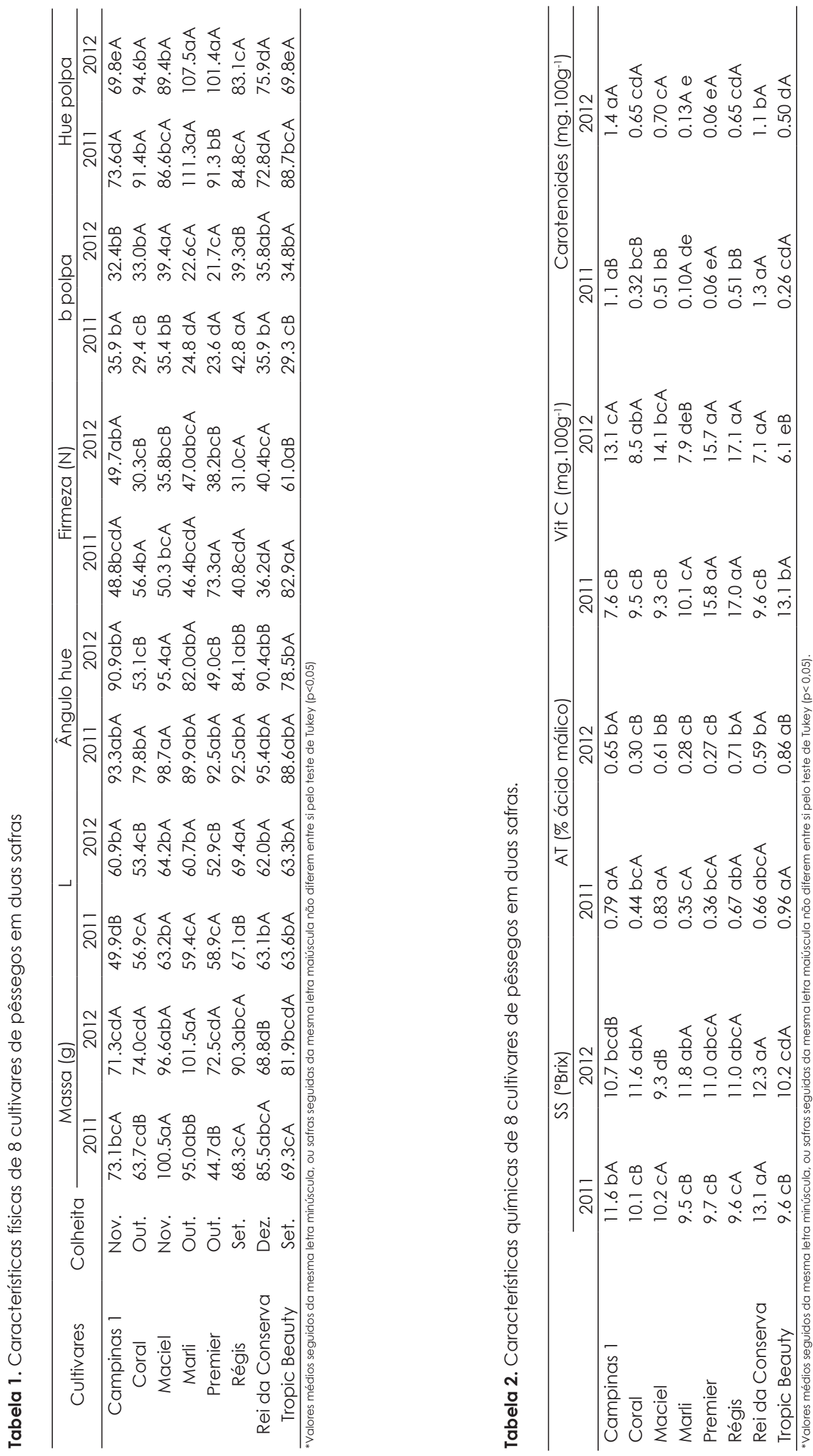
Quanto à coloração da epiderme dos frutos, a coordenada $a^{*}$ varia do verde $(-60)$ ao vermelho (+60); a coordenada b* vai do azul $(-60)$ ao amarelo (+60). A coordenada ho (ângulo hue) varia de 0 a $360^{\circ}$, sendo $0^{\circ}$ vermelho, $90^{\circ}$ - amarelo, $180^{\circ}$ - verde e $270^{\circ}$ azul. De acordo com a tabela 2, observaram-se menores valores de ângulo Hue na safra de 2012, o que indica maiores valores de "a" em relação $a$ "b" e, consequentemente, epiderme com mais coloração vermelha. Nesta safra se destacaram as cultivares Coral e Premier com ângulo hue médio de $53,1^{\circ}$ e $49^{\circ}$, respectivamente; indicando que estas cultivares apresentaram coloração mais próximo de vermelho intenso, característica interessante para frutos destinados ao mercado de mesa, vez que os consumidores tem preferência por pêssegos com tonalidade vermelho na epiderme.

A luz solar é essencial para a produção de pigmentos antociânicos, os quais determinam a coloração vermelha da epiderme de algumas frutas, como pêssegos, maçãs, cerejas, ameixas, uvas, entre outras (Wagner Júnior et al., 2011) e, pela Tabela 1, verifica-se que, no geral, em 2012 o número de horas de brilho solar foi maior que em 2011. Pela Figura 1, verifica-se que, no geral, em 2012 o número de horas de brilho solar foi maior que em 2011 . Houve comportamentos diferentes entre as cultivares e safras em relação à coloração da polpa (Tabela 1).

As cultivares Premier e Tropic Beauty tiveram firmeza de polpa maior do que as demais, na safra de 2011, apresentando potencial póscolheita em relação a esta característica, uma vez que, segundo Wagner Júnior et al. (2011), a firmeza da polpa está relacionada à resistência ao transporte e à vida de prateleira dos frutos. De acordo com Chitarra \& Chitarra (2005), a firmeza da polpa é uma das características da textura e corresponde ao grau de resistência dos tecidos vegetais à compressão; sendo considerada como um dos principais atributos de qualidade e em conjunto com outros parâmetros é utilizada para a avaliação da vida útil dos produtos hortícolas. Após a colheita o teor de cálcio ligado às pectinas tem papel importante na manutenção da firmeza da polpa de frutas como o pêssego, a qual decresce com o avanço da maturação.

A cultivar Rei da Conserva, foi significativamente superior às demais para sólidos solúveis (SS) nas duas safras (Tabela 3), seguida pelas cultivares Coral e Marli na safra de 2012. A cultivar Rei da Conserva é muito utilizada para o processamento industrial e frutos com maiores teores de açúcares totais são preferidos para o consumo direto e para a industrialização, uma vez que esses açúcares conferem sabor mais adocicado ao produto. A explicação mais provável para esse fato deve-se às temperaturas de máximo (Tmax) terem sido superiores nos meses de Outubro e Dezembro (Tabela 1), que foi o período de maturação e colheita dessas cultivares e também a características específicas da referida cultivar. Segundo Wagner Júnior et al. (2010), temperaturas altas durante o dia e amenas no período noturno são a principal causa climática para o aumento do teor de açúcares em pêssegos, além de fatores metabólicos e genéticos.

A acidez total variou consideravelmente entre cultivares, sendo os menores teores observados em frutos das cultivares Marli e Premier em ambas as safras e os maiores teores nos frutos das cultivares Campinas 1, Maciel e Tropic Beauty na safra de 2011 e Tropic Beauty na safra de 2012. Matias et al. (2011), avaliando frutos de 17 famílias de pessegueiro na geração $\mathrm{F}_{2}$ em Araponga/MG, observaram que os teores de acidez variaram de 0,20 a $0,76 \%$ enquanto no presente estudo essa variação ocorreu entre 0,35 e $0,96 \%$.

Os valores de vitamina C foram estatisticamente diferentes entre cultivares e safras (Tabela 2), devido às características intrínsecas de cada cultivar em estudo. Nas duas safras avaliadas se destacaram as cultivares Premier com valores de vitamina $C$ de 15,8

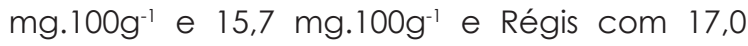
mg.100 $\mathrm{g}^{-1}$ e $17,1 \mathrm{mg}^{1} 100 \mathrm{~g}^{-1}$ nas safras de 2011 e 2012, respectivamente. De acordo com Segantini et al. (2012), em frutas, além de variar entre cultivares, os teores de vitamina $\mathrm{C}$ podem variar em função de outros fatores como tratos culturais e diferentes locais de cultivo.

Maior disponibilidade hídrica proporciona maior produção de ácido 
ascórbico pela planta até certo limite, a partir do qual o excesso hídrico é prejudicial; chuvas excessivas provocam a formação de frutos aquosos e menos ricos em açúcar e vitamina C (Motta et al., 2015). A vitamina C é um importante antioxidante natural, pois absorvem radicais livres e inibem a cadeia de iniciação ou interrompem a cadeia de propagação das reações oxidativas promovidas pelos radicais (Silva et al., 2010).

Os maiores teores de carotenoides foram encontrados nos frutos das cultivares Campinas

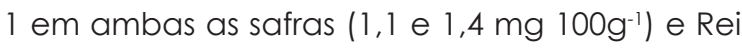

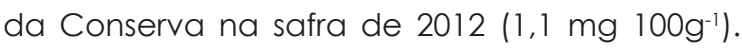
Os valores encontrados no presente trabalho foram superiores aos observados em pêssegos produzidos em São Manuel-SP por Segantini et al. (2012), exceto para a cultivar Premier. O conteúdo de carotenoides de frutos e vegetais pode ser afetado por uma série de fatores como: o grau de maturação, o tipo de solo e as condições de cultivo, as condições climáticas, a variedade, a parte da planta consumida, o efeito dos agrotóxicos, a exposição à luz solar, as condições de processamento e a estocagem (Silva et al., 2014).

O ângulo hue da polpa mostrou a maior correlação significativa (0.92) com o teor de carotenoides totais (CT) (Tabela 3), indicando que a polpa de fruta com menores $\mathrm{h}^{\circ}$ têm maiores quantidades de carotenoides totais. A coordenada b da polpa (0.64) também se destaca entre as características associadas com carotenoides totais, sugerindo que a polpa de fruta com maiores $b$ têm maiores quantidades de CT (Tabela 3). Resultados semelhantes foram encontrados por Matias et al. (2014) em pêssego. A concentração de carotenoides totais determina a cor amarela da polpa em Siriguela (Spondias purpurea), que foi confirmado por análise colorimétrica (Costa et al., 2010), e a variação na cor da polpa entre as variedades de laranja é devido a variação no quantidade dos diferentes carotenoides (Gama \& Sylos, 2005). Maiores valores de sólidos solúveis foram associados com maiores teores de carotenoides no presente trabalho (Tabela 3).

Tabela 3. Correlação fenotípica entre 10 características avaliadas em oito cultivares de pêssego, nas safras de 2011 e 2012.

\begin{tabular}{|c|c|c|c|c|c|c|c|c|c|c|}
\hline Variáveis ${ }^{(1)}$ & L casca & $h^{\circ}$ casca & b polpa & $\mathrm{h}^{\circ}$ polpa & MF & FIR & SS & AT & Vit C & CT \\
\hline L casca* & 1 & 0.566 & $0.637^{*}$ & -0.117 & 0.48 & -0.198 & -0.197 & 0.556 & 0.03 & 0.028 \\
\hline $\mathrm{h}^{\circ}$ casca* $^{*}$ & & 1 & 0.584 & -0.469 & $0.647^{*}$ & -0.262 & 0.133 & 0.611 & -0.164 & 0.565 \\
\hline b polpa* & & & 1 & $-0.706^{*}$ & 0.212 & -0.448 & 0.065 & $0.705^{*}$ & 0.364 & $0.642 *$ \\
\hline$h^{\circ}$ polpa* & & & & 1 & 0.275 & 0.223 & -0.468 & $-0.622 *$ & -0.414 & $-0.921^{* *}$ \\
\hline MF & & & & & 1 & -0.278 & -0.199 & 0.138 & -0.384 & 0.045 \\
\hline FIR & & & & & & 1 & -0.423 & 0.275 & -0.571 & -0.366 \\
\hline SS & & & & & & & 1 & -0.158 & 0.437 & $0.634^{*}$ \\
\hline AT & & & & & & & & 1 & -0.146 & 0.49 \\
\hline Vit C & & & & & & & & & 1 & \begin{tabular}{|l|}
0.305 \\
\end{tabular} \\
\hline $\mathrm{CT}$ & & & & & & & & & & 1 \\
\hline
\end{tabular}

(1) L casca, $h^{\circ}$ casca, b polpa e ho polpa: coordenadas de cor da casca e polpa; MF: massa do fruto (g); FIR: firmeza (N); SS: sólidos solúveis (\%); AT: acidez titulável (\% de ácido málico); Vit C: vitamina C (mg de ácido ascórbico $.100 \mathrm{~g}^{-1}$ de polpa); CT: carotenoides totais (mg. $100 \mathrm{~g}^{-1}$ de polpa). ${ }^{* * *}$ Significativo a 5 e $1 \%$ de probabilidade pelo teste t, respectivamente.

\section{Conclusões}

Foram observadas diferenças entre as características avaliadas nas duas safras avaliadas, sendo as maiores variações observadas na firmeza da polpa e nos teores de vitamina $\mathrm{C}$ e de carotenoides totais.

A tonalidade amarela da polpa do pêssego está associada com carotenoides totais.

As cultivares Maciel e Marli produzem frutos com maiores valores de massa, 'Tropic Beauty' com maior firmeza e 'Rei da Conserva',
'Coral' e 'Marli' com maiores teores de sólidos solúveis. As cultivares Premier e Régis se destacaram com maiores teores de vitamina C, enquanto as cultivares Campinas 1 e Rei da Conserva apresentaram os maiores teores de carotenoides.

\section{Agradecimentos}

Ao CNPq, CAPES e FAPEMIG pelo apoio financeiro. 


\section{Referências}

Chitarra, M. I. F., Chitarra, A. B. 2005. Pós-colheita de frutas e hortaliças: fisiologia e manuseio. 2. ed. rev. e ampl. Lavras: UFLA, 785 p.

Citadin, I., Scariotto, S., Sachet, M.R., Rosa, F.J., Raseira, M. do C.B., Wagner Júnior, A. 2014. Adaptability and stability of fruit set and production of peach trees in a subtropical climate. Scientia Agricola 71: 133-139.

Cruz, C.D. 2013. GENES - a software package for analysis in experimental statistics and quantitative genetics. Acta Scientiarum. Agronomy 35: $271-$ 276.

Della Bruna, E., Moreto, A.L., Dalbó, M.A. 2012. Uso do coeficiente de repetibilidade na seleção de clones de pessegueiro para o litoral sul de Santa Cantarina. Revista Brasileira de Fruticultura 34: 206-215.

Costa, M.G.P., Figueiredo, F.J., Silva, Q.J., Lima, V. L.A.G. 2010. Carotenóides totais e caracterização cromática de polpas de frutos de genótipos de cirigueleiras cultivadas no banco de germoplasma do IPA. In: Jornada de Ensino, Pesquisa e Extensão, Recife. Anais... UFRPE, Recife, Brasil. CD-ROM.

Gama, J.J.T., Sylos, C.M. 2005. Major carotenoid composition of Brazilian Valencia Orange juice: identification and quantification by HPLC. Food Research International 38: 899-903.

Gullo, G., Motisi, A., Zappia, R., Dattola, A. Diamanti, J., Mezzetti, B. 2014. Rootstock and fruit canopy position affect peach [Prunus persica (L.) Batsch] (cv. Rich May) plant productivity and fruit sensorial and nutritional quality. Food Chemistry 153: 234-242.

IBGE-Instituto Brasileiro de Geografia e Estatística. Produção Agrícola Municipal. 2013. http://www. sidra.ibge.gov.br <Acesso em 04 mai. 2015?

Leite, G.A., Medeiros, E.V., Mendonça, V. Moraes, P.L.D., Lima, L.M., Xavier, I.E. 2010. Qualidade pós-colheita da banana 'Pacovan' comercializada em diferentes estabelecimentos no município de Mossoró-RN. Revista Brasileira de Ciências Agrárias 5: 322-327.

Leonel, S., Tecchio, M.A. 2011. Produção e sazonalidade de pessegueiro e nectarineira sob florescimento espontâneo e com cianamida hidrogenada e óleo mineral. Revista Brasileira de Fruticultura Especial: 227-234.

Lichtenthaler, H.K. 1987. Chlorophylls and carotenoids: Pigments of photosynthetic biomembranes. Methods in Enzymology 148: 349382.
Matias, R.G.P., Bruckner, P.C.S., Silva, D.F.P., Silva, J.O. da C. 2014. Repeatability, correlation and path analysis of physical and chemical characteristics of peach fruits. Revista Brasileira de Fruticultura 36: 971-979.

Matias, R.G.P., Silva, D.F.P., Ribeiro, M. R., Silva, J. O. da C., Oliveira, S. P. de, Bruckner, C. H. 2014. Características de frutos de pessegueiros cultivados na Zona da Mata de Minas Gerais. Ciência Rural 44: 971-974.

Matias, R.G.P., Bruckner, C.H., Santos, C.E.M., Dias, D.C.S.F., Silva, D.F.P., Assunção, W., Ribeiro, M.R. 2011. Qualidade de pêssegos provenientes de plantas selecionadas para capacidade de brotação. Revista Brasileira de Agropecuária Sustentável 1: 45-49.

McGuire, R.G. 1992. Reporting of objective color measurements. HortScience 27: 1254-1260.

Mestre, L., Reig, G., Betrán, J.A., PinocheT, J., Ángeles, M.A. 2015. Influence of peach - almond hybrids and plum-based rootstocks on mineral nutrition and yield characteristics of 'Big Top' nectarine in replant and heavy-calcareous soil conditions. Scientia Horticulturae 192: 475-481.

Motta, J. D., Queiroz, A. J. de M., Figueirêdo, R. M. F. de; Sousa, K. dos S. M. de. 2015. Índice de cor e sua correlação com parâmetros físicos e físico-químicos de goiaba, manga e mamão. Comunicata Scientiae 6: 74-82.

Segantini, D.M., Leonel, S., Lima, G.P.P., Costa, S.M., Ramos, A.M.R.P. 2012. Caracterização da polpa de pêssegos produzidos em são ManuelSP. Ciência Rural 42: 52-57.

Silva, D.F.P., Cremasco, J.P.G., Matias, R.G.P., Silva, J.O. da C., Bruckner, C.H. 2014. Degradação de antioxidantes e sólidos solúveis em polpa de pêssego. Magistra 26: 1136-1140.

Silva, D. F. P. da, Silva, J. O. da C., Matias, R. G. P., Ribeiro, M. R., Bruckner, C. H. 2013. Correlação entre características quantitativas e qualitativas de frutos de pessegueiros na geração F2 cultivados em região subtropical. Revista Ceres 60: 53-58.

Silva, L.M., Costa, R.S., Santana, A.S., Koblitz, M.G.B. 2010. Compostos fenólicos, carotenóides e atividade antioxidante em produtos vegetais. Semina. Ciências Agrárias 31: 669-682.

Souza, A. V., Kohatsu, D. S., Lima, G. P. P., Vieites, R. L. 2009. Conservação pós-colheita de pêssego com o uso da refrigeração e da irradiação. Revista Brasileira de Fruticultura 31: 1184-1 189.

Steel, R.G.D., Torrie, J. H. 1960. Principles and procedures of statistics. New York: McGraw-Hill, $418 \mathrm{p}$. 
Toralles, R.T., Vendruscolo, J.L., Malgarim, B.M., Cantilhano, R.F., Schunemann, A.P.P., Antunes, P.L. 2008. Características físicas e químicas de cultivares brasileiras de pêssegos em duas safras. Revista Brasileira de Agrociência 14: 327-338.

Wagner Júnior, A., Bruckner, C.H., Cantín, M.C., Sánchez, M.A.M., Santos, C.E.M. 2011 . Seleção de progênies e genitores de pessegueiro com base nas características dos frutos. Revista Brasileira de Fruticultura 33: 170-179.

Wagner Júnior, A., Bruckner, C. H., Silva, J. O. da C. e, Santos, C. E. M. dos, Pimentel, L. D., Mazaro, S. M. 2010. Adaptação de genótipos de pessegueiro F2 para condições de baixo acúmulo de frio hibernal. Bragantia 69: 815-822. 